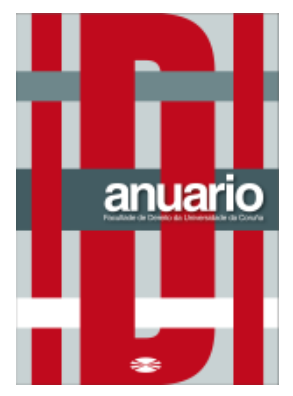

Anuario da Facultade de Dereito da Universidade da Coruña

Vol. 24 (2020), pp. 192-212

ISSNe: 2530-6324 || ISSN: 1138-039X

DOI: https://doi.org/10.17979/afdudc.2020.24.0.7485

\title{
LIBERTAD DE EXPRESIÓN EN EL TRABAJO Y REPRESALIAS POR DENUNCIAR IRREGULARIDADES
}

\section{FREEDOM OF EXPRESSION AT WORK AND THE RETALIATIONS AGAINST WHISTLEBLOWING}

\author{
RICARDO PEDRO RON LATAS \\ Profesor Titular de Universidad - Universidade da Coruña \\ Magistrado suplente TSJ/Galicia \\ https://orcid.org/0000-0002-1526-2316 \\ JOSÉ FERNANDO LOUSADA AROCHENA \\ Magistrado especialista de lo social - TSJ/Galicia \\ Doctor en Derecho / Graduado Social \\ https://orcid.org/0000-0002-4629-0539
}

Recibido: $10 / 07 / 2020$

Aceptado: 23/10/2020

Resumen: Hoy en día, uno de los temas estrella en el ámbito jurídico laboral es el de la libertad de expresión de los trabajadores. Se trata de un complejo tema que ha recibido un importante espaldarazo normativo tras la publicación de la Directiva (UE) 2019/1937 del Parlamento Europeo y del Consejo, de 23 de octubre de 2019, relativa a la protección de las personas que informen sobre infracciones del derecho de la unión (Directiva Whistleblowing). A la vista de lo dispuesto en ella, resulta conveniente efectuar un análisis de la jurisprudencia sobre libertad de expresión en el trabajo y represalias por denuncia de irregularidades.

Palabras clave: Libertad de expresión, Amparo legal, Derecho de la Unión Europea, Directiva Whistleblowing, Denuncia de irregularidades.

Abstract: Nowadays, one of the starring themes in the legal-labour field is the freedom of expression for workers. This is a complex issue that has received an important normative 
boost after the publication of the Directive (EU) 2019/1937 of the European Parliament and of the Council of 23 October 2019 on the protection of persons who report breaches of Union law (Whistleblowing Directive). In accordance with the provisions of the Directive, it is appropriate an analysis of the case law about the freedom of expression at work and protection against retaliation for reporting misconduct.

Keywords: Freedom of expression, Legal protection, European Union law, Whistleblowing Directive, Whistleblowing.

Sumario: I. INTRODUCCIÓN. II. UN BREVE REPASO A LA JURISPRUDENCIA CONSTITUCIONAL SOBRE LIBERTAD DE EXPRESIÓN EN EL TRABAJO PARA APRECIAR LA CONTINUIDAD DE LA DOCTRINA. III. LA SENTENCIA 146/2019, DE 26 DE NOVIEMBRE, DEL TRIBUNAL CONSTITUCIONAL: SU SUPUESTO DE HECHO Y LA SOLUCIÓN A QUE SE LLEGA EN SU FALLO. IV. LO QUE ES MÁS DESTACABLE: EL USO DE LA DENUNCIA INTERNA COMO ELEMENTO PARA LA VALORACIÓN DE LA BUENA FE Y LA DIRECTIVA WHISTLEBLOWING. BIBLIOGRAFÍA.

\section{INTRODUCCIÓN}

A nuestro entender, uno de los temas estrella hoy en día en el ámbito jurídico laboral es el de la libertad de expresión de los trabajadores. Se trata de una materia que ha recibido un importante espaldarazo normativo tras la publicación de la Directiva (UE) 2019/1937 del Parlamento Europeo y del Consejo, de 23 de octubre de 2019, relativa a la protección de las personas que informen sobre infracciones del derecho de la unión (Directiva Whistleblowing), cuya finalidad no es otra que la de reforzar la aplicación del Derecho y las políticas de la Unión en ámbitos específicos mediante el establecimiento de normas mínimas comunes que proporcionen un elevado nivel de protección de las personas que informen sobre infracciones del Derecho de la Unión ${ }^{1}$.

La realidad judicial nos demuestra, sin embargo, que la libertad de expresión de los trabajadores —así como las posibles represalias derivadas del ejercicio de ese derecho fundamental — ha venido ocupando a nuestros tribunales laborales desde hace décadas. El último ejemplo lo encontramos en una STC 146/2019, de 26 de noviembre ${ }^{2}$, donde se aborda un tema que, dentro de su doctrina, reúne las características como para denominarse

${ }^{1}$ Sobre la citada Directiva, véase LOUSADA AROCHENA, J.F. y RON LATAS, R.P., La protección laboral frente a las represalias por la denuncia de irregularidades en la empresa (Whistleblowing), Albacete, 2020, passim.

${ }^{2}$ STC 146/2019, de 25 de noviembre. 
ya como clásico. Para comprobarlo basta con reproducir la síntesis analítica con la que esta resolución se presenta en la página web del Tribunal Constitucional: "Vulneración del derecho a la libertad de expresión: despido disciplinario de un trabajador por criticar la gestión empresarial del centro de trabajo en el que prestaba sus servicios (STC 181/2006)"3.

Se trata, en efecto, de una sentencia sobre el derecho a la libertad de expresión en el marco de un contrato de trabajo, sobre lo cual hay previa jurisprudencia constitucional (y así lo delata la propia síntesis analítica). Pero no solo hay previa jurisprudencia constitucional, tan clásico es el tema que también encontramos doctrina del Tribunal Europeo de Derechos Humanos ${ }^{4}$ y del Tribunal de Justicia de la Unión Europea ${ }^{5}$, además de numerosas sentencias sobre la temática en la jurisdicción social (y, por supuesto, numerosos estudios doctrinales de una gran profundidad de alguno de los cuales iremos dando cuenta a lo largo de nuestra exposición).

De toda esa amplia panoplia de doctrina judicial, resulta especialmente destacable la construida por el Tribunal Europeo de Derechos Humanos a propósito de lo dispuesto en el art. 10 del Convenio de Roma ${ }^{6}$, que entiende que "la libertad de expresión constituye uno de los fundamentos esenciales de una sociedad democrática, una de las condiciones primordiales de su progreso y del desarrollo de cada individuo"7, siendo la misma "válida no solamente para las «informaciones» o «ideas» acogidas favorablemente o consideradas inofensivas o indiferentes, sino también para aquellas que chocan, ofenden o inquietan: así lo quieren el pluralismo, la tolerancia y el espíritu de apertura, sin los cuales no es una

${ }^{3}$ https://hj.tribunalconstitucional.es/es/Resolucion/Show/26117\#ficha-tecnica (consulta: 15/06/2020).

${ }^{4}$ En este ámbito, "el CEDH parte de un concepto amplio de la libertad de expresión, incluyendo en el mismo la libertad de opinión, la libertad de información (dentro de la cual, incluimos la libertad de prensa), la libertad de creación artística o científica, el lenguaje (o discurso) simbólico, la libertad de expresión comercial, la libertad de expresión profesional, la libertad de prensa, la libertad de creación de medios de comunicación, o la llamada libertad de antena” (CLIMENT GALLART, J.A., La jurisprudencia del Tribunal Europeo de Derechos Humanos sobre la libertad de expresión y el derecho al honor, Tesis Doctoral, Valencia, 2015, http://roderic.uv.es, pág. 146, consulta 01/05/2020).

${ }^{5}$ Conviene advertir, no obstante, que la doctrina acerca de la libertad de expresión construida por el Tribunal Europeo de Derechos Humanos en interpretación del art. 10 del Convenio de Roma fue acogida en un principio del el Tribunal de Justicia de la Unión Europea, y así "la libertad de expresión y la jurisprudencia del TEDH ya habían venido sirviendo, y con solvencia, como parámetro de escrutinio de la adecuación iusfundamental de restricciones y afectaciones de los derechos de comunicación y opinión en el ámbito de aplicación del Derecho de la Unión” (RODRÍGUEZ-IZQUIERDO SERRANO, M. "La liberta de expresión y la jurisprudencia del Tribunal de Justicia de la Unión Europea”, en Estudios de Deusto, Vol. 62/2, 2014, pág. 96).

${ }^{6}$ Cuyo apartado 1 indica lo siguiente: “1. Toda persona tiene derecho a la libertad de expresión. Este derecho comprende la libertad de opinión y la libertad de recibir o de comunicar informaciones o ideas, sin que pueda haber injerencia de autoridades públicas y sin consideración de fronteras. El presente artículo no impide que los Estados sometan a las empresas de radiodifusión, de cinematografía o de televisión a un régimen de autorización previa”.

7 STEDH. Caso Palomo Sanchez y Otros contra España. Sentencia de 12 septiembre 2011. TEDH 2011168. 
«sociedad democrática»" informaciones expresadas..., su modo de expresión”.

No obstante, el derecho a la libertad de expresión constituye una regla que como tal "está sujeta a excepciones que, sin embargo, requieren una interpretación estricta, y la necesidad de cualquier restricción debe ser acreditada de manera convincente” ${ }^{10}$. Se trata, no obstante, de una obligación esta de preservar el equilibrio entre los distintos intereses concurrentes, que "gracias al contacto directo y constante con la realidad del país, los tribunales y jueces de un Estado se encuentran mejor situados que el Juez Internacional para precisar dónde se establece, en un momento dado, el equilibrio justo a preservar ... especialmente cuando se trata de ponderar un conflicto de intereses privados" ${ }^{11}$.

Por lo que al derecho de la Unión Europea se refiere, la libertad de expresión encuentra una doctrina realmente rácana en el seno de la jurisprudencia europea. Las resoluciones del Tribunal de Justicia de la Unión Europea al respecto, además de escasas, son ciertamente parcas a la hora de establecer un marco jurisprudencial consolidado alrededor del art. 11 de la Carta de Derechos Fundamentales de la Unión ${ }^{12}$. La razón no es otra que la ausencia hasta épocas recientes de un marco normativo propio. La doctrina destaca en este sentido que "como todos los derechos que han tenido algún tratamiento en la jurisprudencia del Tribunal de Luxemburgo, haya sido el mismo sustantivo o tan solo tangencial, la libertad de expresión ha pasado en la doctrina del juez europeo por las etapas comunes a todos ellos" ${ }^{13}$.

Así, la "libertad de expresión es acogida inicialmente por el Tribunal de Justicia como elemento indispensable de esas tradiciones y, casi sin solución de continuidad, o más bien superando resistencias iniciales, es puesta bajo el amparo del artículo 10 del Convenio de Roma, mínimo común de la tradición común y siguiendo la interpretación que emana de la Corte de Estrasburgo"14, y dentro "de ese marco se ha mantenido la libertad de expresión en las alegaciones ante el Tribunal de Justicia, así como en las argumentaciones del mismo en respuesta y solución a los conflictos planteados, hasta fecha muy reciente” ${ }^{15}$. El cambio se produce "cuando esas referencias recurrentes han pasado a estar acompañadas por invocaciones directas al artículo 11 de la Carta de Derechos Fundamentales de la Unión,

${ }^{8}$ STDEH. Caso Palomo Sanchez y Otros contra España. Sentencia de 12 septiembre 2011. TEDH $2011 \backslash 68$.

${ }^{9}$ STDEH. Caso Palomo Sanchez y Otros contra España. Sentencia de 12 septiembre 2011. TEDH $2011 \backslash 68$.

${ }^{10}$ STDEH. Caso Palomo Sanchez y Otros contra España. Sentencia de 12 septiembre 2011. TEDH $2011 \backslash 68$.

${ }^{11}$ STDEH. Caso Palomo Sanchez y Otros contra España. Sentencia de 12 septiembre 2011. TEDH $2011 \backslash 68$.

${ }^{12}$ Donde se establece lo siguiente: "Toda persona tiene derecho a la libertad de expresión. Este derecho comprende la libertad de opinión, la libertad de recibir o comunicar informaciones o ideas sin que pueda haber injerencia de autoridades públicas y sin consideración de fronteras”.

${ }^{13}$ RODRÍGUEZ-IZQUIERDO SERRANO, M., "La libertad de expresión ...”, cit., pág. 96.

${ }^{14}$ RODRÍGUEZ-IZQUIERDO SERRANO, M., "La libertad de expresión ...”, cit., pág. 97.

${ }^{15}$ RODRÍGUEZ-IZQUIERDO SERRANO, M., “La libertad de expresión ...”, cit., pág. 96. 
cuando no por fin centradas y encuadradas en esta norma propia del Derecho de la

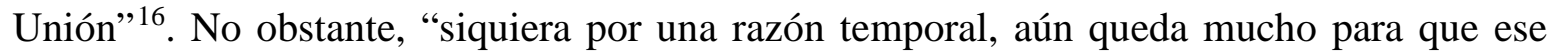
artículo 11 de la Carta alcance el volumen de citas que en un repaso cronológico acumula el artículo 10 del Convenio" ${ }^{17}$.

En consecuencia, un repaso a la jurisprudencia comunitaria relativa al derecho a la libertad de expresión, y más en concreto, a su repercusión en el ámbito de las relaciones laborales, revela que su núcleo doctrinal no es otra cosa más que el reflejo de la doctrina del Tribunal Europeo de Derechos Humanos, sin que además puedan encontrarse resoluciones relevantes en dicho ámbito. A ello debe añadirse, por lo que a nosotros interesa, la diferente concepción del derecho controvertido según la competencia territorial del tribunal de que se trate. De ello resulta que "los contextos fácticos y normativos de ponderación en los que se inserta la libertad de expresión en ... sede jurisdiccional son distintos de aquellos a los que la justicia constitucional nos tiene acostumbrados”18.

Así, mientras que la doctrina del Tribunal Europeo de Derechos Humanos presenta ciertas conexiones con la de nuestro Tribunal Constitucional, no sucede lo mismo con la jurisprudencia del Tribunal de Justicia de la Unión Europea. Lo habitual “en los conflictos referentes a esta libertad pública, al menos en la jurisprudencia más conocida de nuestros Tribunales Constitucionales o del Tribunal Europeo de Derechos Humanos, es encontrarnos ante una de estas dos situaciones: por un lado, una situación en la que la libertad de expresión, o cualquier otra libertad comunicativa, está en un vértice, mientras que los derechos de la personalidad -honor, intimidad y propia imagen- están en el otro, de manera que es necesario realizar un juicio de ponderación que facilite la decisión sobre el o los derechos a proteger, siendo así que los criterios de tal ponderación están determinados por factores como la relevancia informativa o la veracidad del contenido, la dimensión pública o particular de la persona aludida, la capacidad de difusión del medio transmisor o la neutralidad en la presentación de la noticia, entre otros; o, por otro lado, una situación en la que hay una injerencia en el ejercicio del derecho a la libre opinión o información a través de una actuación directa, o una afectación a su contenido a través de una regulación específica o relacionada con el ámbito de realización de la libertad. En la segunda situación, que caracteriza una afectación o vulneración del derecho derivada de la actuación de un poder público, lo que se exige es un juicio de constitucionalidad que aplique los criterios de escrutinio correspondientes, entre los que se encuentran, de nuevo entre otros, la necesidad de la medida, la medición de la proporcionalidad en el sacrificio del derecho, el respeto al contenido esencial o a los bienes y objetivos constitucionales protegidos por el derecho o, en los juicios más depurados, el efecto inhibitorio de la restricción” ${ }^{19}$. Sin embargo, cuando la libertad de expresión se esgrime ante el Tribunal de Justicia de la Unión Europea, “la misma se enfrenta a situaciones bien distintas, sobre todo por ser situaciones en las que las

${ }^{16}$ RODRÍGUEZ-IZQUIERDO SERRANO, M., “La libertad de expresión ...”, cit., pág. 96.

${ }^{17}$ RODRÍGUEZ-IZQUIERDO SERRANO, M., "La libertad de expresión ...”, cit., pág. 96.

${ }^{18}$ RODRÍGUEZ-IZQUIERDO SERRANO, M., "La libertad de expresión ...”, cit., pág. 99.

${ }^{19}$ RODRÍGUEZ-IZQUIERDO SERRANO, M., “La libertad de expresión ...”, cit., pág. 99. 
que las competencias atribuidas a la Unión tienen un gran protagonismo y también porque es sencillo que actores privados, operadores económicos o usuarios de servicios, entren en el juego de las restricciones indirectas que amenazan la libre comunicación. Así, las libertades de opinión e información llegan a medirse, al igual que otros muchos derechos fundamentales de tradición constitucional común, con las libertades económicas, es decir, con las libertades de circulación del mercado europeo en sus distintas variantes. También se ven encuadradas en contextos de ponderación predefinidos en regulaciones europeas aplicables, como ocurre con las directivas sobre protección de datos, comercio electrónico o derechos de autor. Y para nuestras libertades protagonistas, como factor diferencial, las fronteras estatales que marcan los márgenes de apreciación de lo necesario y lo proporcional, así como de los sistemas de comunicación pública tradicionales, aparecen alteradas por obra y gracia de la unidad del espacio europeo en su dimensión económica, cuando no más allá de cuestiones de mercado” ${ }^{20}$.

Sea como fuere, a partir de aquí, y siempre con relación a nuestro Tribunal Constitucional, siempre resulta conveniente repasar su doctrina por muy consolidada que esté, y así lo haremos para contextualizar lo que se dirá seguidamente. Pero no se queda ahí el alcance de la STC 146/2019, de 26 de noviembre, que constituirá el nudo gordiano de nuestra exposición. La novedad que atrae nuestra atención es que en ella se analiza la relevancia de la utilización de una denuncia interna para apreciar la legitimidad del ejercicio del derecho a la libertad de expresión por la persona trabajadora. No se trata de una novedad absoluta, pues, como se verá más adelante, ya había algunos precedentes anteriores en la propia jurisprudencia constitucional. Pero sí es verdad que este aspecto conecta con la reciente regulación a nivel comunitario de la protección de las personas denunciantes de irregularidades a través de la Directiva (UE) 2019/1937 del Parlamento Europeo y del Consejo, de 23 de octubre de 2019, relativa a la protección de las personas que informen sobre infracciones del Derecho de la Unión, la llamada Directiva Whistleblowing (que hemos analizado en una reciente publicación) ${ }^{21}$.

En consecuencia, nuestro estudio comenzará por analizar la previa jurisprudencia constitucional (Epígrafe I), luego la propia STC 146/2019, de 26 de noviembre (Epígrafe II), para finalizar parándonos en lo que tiene de más destacado a la vista en particular de la reciente Directiva Whistleblowing (Epígrafe III).

\section{UN BREVE REPASO A LA JURISPRUDENCIA CONSTITUCIONAL SOBRE LIBERTAD DE EXPRESIÓN EN EL TRABAJO PARA APRECIAR LA CONTINUIDAD DE LA DOCTRINA}

A la vista de que la STC 146/2019, de 26 de noviembre, núcleo central de este estudio supone una continuidad respecto a la jurisprudencia anterior (con particular

\footnotetext{
${ }^{20}$ RODRÍGUEZ-IZQUIERDO SERRANO, M., “La libertad de expresión ...”, cit., pág. 99.

${ }^{21}$ LOUSADA AROCHENA, J.F. y RON LATAS, R.P., La protección laboral ..., cit., passim.
} 
referencia a la STC 181/2006, de 20 de julio) resulta conveniente realizar un repaso a sus aspectos esenciales, que se podrían resumir en tres aspectos ${ }^{22}$ :

(1) Un primer aspecto esencial de la jurisprudencia constitucional en la materia es la existencia de un doble límite en el ejercicio del derecho fundamental a la libertad de expresión por las personas trabajadoras, que ya aparece debidamente expuesto en una sentencia de dicha jurisprudencia constitucional que debe ser considerada como iniciática. Nos estamos refiriendo a la ya añeja STC 120/1983, de 5 de diciembre. Su supuesto de hecho era una huelga en un colegio durante los exámenes extraordinarios de septiembre, de ahí que, para realizarlos y corregirlos, la empresa realizó nuevas contrataciones, ante lo cual el comité de huelga alertó de que los profesores contratados no estaban capacitados y que había sospechas de irregularidades, y eso llevó al despido de todos sus miembros. De esta sentencia lo que más destaca es — como se ha apuntado - el doble límite que establece, en el ámbito de las relaciones laborales, al derecho a la libertad de expresión consagrado constitucionalmente. Con carácter general, la libertad de expresión no es "un derecho limitado, pues claramente se encuentra sometido a los límites que el artículo 20.4 de la Constitución Española establece, y en concreto a la necesidad de respetar el honor de las personas, que también como derecho fundamental consagra el artículo 18.1”. Además de este límite de genérico, "la existencia de una relación contractual entre trabajador y empresario genera un complejo de derechos y obligaciones recíprocas que condiciona, junto a otros, también el ejercicio del derecho a la libertad de expresión, de modo que manifestaciones del mismo que en otro contexto pudieran ser legítimas no tienen por qué serlo necesariamente dentro del ámbito de dicha relación”. Y es que, aunque el Tribunal Constitucional advierte que no hay "un genérico deber de lealtad, con su significado omnicomprensivo de sujeción del trabajador al interés empresarial, pues ello no es acorde al sistema constitucional de relaciones laborales”, también señala que la base de las relaciones laborales es un "comportamiento mutuo ajustado a las exigencias de la buena fe, como necesidad general derivada del desenvolvimiento de todos los derechos y específica de la relación contractual”. Todo ello le conduce, en el caso concreto, a desestimar el amparo de los huelguistas despedidos en base a dos argumentos: el comité de huelga actuó con animus nocendi y el peligro que las manifestaciones realizadas suponían para la estabilidad de la empresa.

Una posterior sentencia, la STC 88/1985, de 19 de julio, parte de estas premisas, pero aquí con un resultado final bien distinto, lo que ya nos pone en la pista de que estamos

${ }^{22}$ La bibliografía sobre libertad de expresión de expresión en la relación laboral es bastante abundante. Hemos utilizado en particular para la elaboración del presente artículo: DEL REY GUANTER, S., Libertad de expresión e información y contrato de trabajo: Un análisis jurisprudencial, Madrid, 1994; DEL REY GUANTER, S., "La reciente doctrina del Tribunal Constitucional sobre la libertad de expresión e información en la relación laboral: extensión y límites", en AA.VV. (LOUSADA AROCHENA, J.F. [coord.], y MOVILLA GARCÍA, M. [coord.]), Derechos fundamentales y contrato de trabajo, Granada, 1998; GORELLI HERNÁNDEZ, J. e IGARTUA MIRÓ, M.T., "Libertad de información y contrato de trabajo. El problema de sus límites. A propósito de la STC 57/1999, de 12 abril”, Aranzadi Social, vol. V, 1999; PAZOS PÉREZ, A., El derecho a la libertad de expresión y el derecho a la libertad de información en el ámbito laboral, Valencia, 2014. 
ante una jurisprudencia muy casuística y en la que, de manera progresiva, se amplía el ámbito de actuación de la libertad de expresión. En esta ocasión se trataba de las manifestaciones realizadas en un debate televisivo por el jefe clínico de un hospital psiquiátrico gestionado por una fundación privada en orden al sistema asistencial de una comunidad autónoma, afirmando que era arcaico y que había un caos asistencial total; manifestaciones por las cuales el trabajador fue despedido. Nuevamente, el punto de partida del alto tribunal es que el ejercicio de la libertad de expresión "tomando como contenido aspectos generales o singulares del funcionamiento y actuación de la empresa en la que presta servicios”, se debe enmarcar “en unas determinadas pautas de comportamiento, que el artículo 7 del Código Civil expresa con carácter general, al precisar que los derechos deberán ejercitarse conforme a las exigencias de la buena fe". Por ello, "la emisión o difusión de opiniones en forma desajustada a lo que constituye una regla de general observancia en el tráfico jurídico convierte en ilícito y abusivo el ejercicio de la libertad de expresión, pudiendo por consiguiente entrar en juego el cuadro de responsabilidades contractuales derivadas del incumplimiento del deber de buena fe". Ahora bien, en este caso gana la libertad de expresión (y se estima el amparo) pues "las opiniones y criterios del demandante discurrieron por los cauces de la normalidad jurídica”.

Otro magnífico ejemplo tanto de la casuística en la cual se mueve esta jurisprudencia constitucional como de la progresiva ampliación del ámbito de actuación de la libertad de expresión lo encontramos en el caso, un tanto estrambótico, de la STC 106/1996, de 12 de junio: en un hospital un capellán celebraba misa todos los domingos; ante la ausencia de asistentes en un determinado domingo, y en la creencia de que ello obedecía a que el personal sanitario estaba en negociación de un convenio colectivo, decidió subir a las plantas a dar la comunión a los enfermos, lo que hizo portando el cáliz y entonando cánticos religiosos; cuando la comitiva llegó a la planta donde estaba prestando sus servicios la trabajadora luego despedida, esta manifestó en voz alta «no sé como no les da vergüenza», «esto parece un picnic», «estos son los humanitarios» y «si mi madre estuviese aquí los denunciaría», lo que pudo ser escuchado por los que se hallaban presentes en dicho lugar, tanto enfermos como familiares y visitadores así como trabajadores, diciéndole, tras dichas expresiones, el capellán que era una «desvergonzada». Ante estos hechos, el Tribunal Constitucional insiste en que "el ejercicio del derecho reconocido en el artículo 20.1 a) CE no está exento de límites, pues claramente se encuentra sometido a los que el apartado 4 del mismo precepto establece”, y en que esos límites encuentran particularidades en el ámbito de las relaciones laborales porque "las manifestaciones de una parte respecto de otra deben enmarcarse en las pautas de comportamiento que se derivan de la existencia de tal relación, pues el contrato entre trabajador y empresario genera un complejo de derechos y obligaciones recíprocas que condiciona, junto a otros, también el ejercicio del derecho a la libertad de expresión, de modo que manifestaciones del mismo que en otro contexto pudieran ser legítimas, no tienen por qué serlo necesariamente en el ámbito de dicha relación”. De este modo, “surge un condicionamiento o límite adicional en el ejercicio del derecho constitucional, impuesto por la relación laboral, que se deriva del principio de buena fe entre las partes en el contrato de 
trabajo y al que estas han de ajustar su comportamiento mutuo. Aunque ello no suponga, ciertamente, la existencia de un deber genérico de lealtad con su significado omnicomprensivo de sujeción del trabajador al interés empresarial, pues ello no es acorde al sistema constitucional de relaciones laborales ... ya que no cabe olvidar la trascendencia del reconocimiento por la Constitución de los derechos fundamentales de la persona, que la acompañan en todas las facetas de la vida de relación y también en el seno de la relación laboral”. Surge así "la necesidad de que las resoluciones judiciales, en casos como el presente, preserven el necesario equilibrio entre las obligaciones dimanantes del contrato para el trabajador y el ámbito modulado, por el contrato, pero en todo caso subsistente, de su libertad constitucional. Pues dada la posición preeminente de los derechos fundamentales en nuestro ordenamiento, esa modulación solo se producirá en la medida estrictamente imprescindible para el correcto y ordenado desenvolvimiento de la actividad productiva. Lo que entraña la necesidad de proceder a una ponderación adecuada, que respete la correcta definición y valoración constitucional del derecho fundamental aquí en juego y de las obligaciones laborales que pueden modularlo. Juicio que permitirá determinar, a la luz de las concretas circunstancias del caso, si la reacción empresarial que ha conducido al despido de la trabajadora es legítima o, por el contrario, esta fue sancionada disciplinariamente por el lícito ejercicio de sus derechos fundamentales, en cuyo caso el despido no podría dejar de calificarse como nulo"; lo que efectivamente conduce, en el supuesto que en esta STC 106/1996, de 12 de junio, se analiza, a la estimación del amparo.

Lo que queda claro a la vista de estas sentencias citadas - y también a la vista de las que se citarán a continuación - es que, según la jurisprudencia constitucional, la conducta de los trabajadores en el marco de los derechos a la libertad de expresión e información se ve sometida a un doble límite: uno genérico, el relativo a cualquier clase de individuos, y otro específico, derivado de su vínculo contractual laboral. De este modo, además de ese límite genérico, "el derecho a la libertad de expresión ... debe conciliarse, cuando se ejerce en el marco de una relación de trabajo, con la lícita protección de los intereses empresariales, deducidos estos conforme a un juicio de ponderación, de manera que las restricciones que hayan de aplicarse habrán de ser adecuadas, imprescindibles y proporcionales a la protección de la libertad de empresa”23. Resulta así, en suma, que en el ámbito laboral "el ejercicio de la indicada libertad [de expresión] no solo está sujeto a ... restricciones genéricas ... sino también a los límites adicionales derivados del vínculo contractual que une a trabajador y empresario"24.

(2) Un segundo aspecto esencial de la jurisprudencia constitucional en la materia es la distinción — no siempre fácil en la práctica — entre libertad de expresión y libertad de información, que ha obligado a reelaborar la relación entre la libertad de expresión y el límite derivado de la buena fe contractual. Tal diferenciación se perfila con claridad en una sentencia de la saga que, por todo ello, se puede calificar de emblemática. Se trata de la

\footnotetext{
${ }^{23}$ STC 181/2006, de 19 de junio.
}

${ }^{24}$ STC 56/2008, de 14 de abril. 
STC 6/1988, de 21 enero. En ella, se declaró la nulidad del despido disciplinario de un trabajador destinado en el gabinete de prensa del Ministerio de Justicia que se había justificado en transgresión de la buena fe contractual por haber aquel denunciado públicamente que, desde la llegada al poder del PSOE, se filtraban noticias de manera privilegiada a la Editorial Prisa. Y se puede calificar de emblemática — como ya hemos dicho_- por dos circunstancias:

- La primera es la diferenciación entre la libertad de expresión y la libertad de información pues es lo cierto que, aunque algunos sectores doctrinales hayan defendido su unificación o globalización, en la Constitución Española se encuentran separados. Conforme al Tribunal Constitucional, ambos derechos presentan "un diferente contenido y es posible señalar también que sean diferentes sus límites y efectos, tanto ad extra como ad intra, en las relaciones jurídicas, especialmente las de carácter laboral, en que quien ejerce el derecho fundamental se puede encontrar unido con otras personas”. Así las cosas, "la libertad de expresión tiene por objeto pensamientos, ideas y opiniones, concepto amplio dentro del que deben incluirse también las creencias y los juicios de valor”, mientras que el derecho a comunicar y recibir libremente información "versa, en cambio, sobre hechos o, tal vez más restringidamente, sobre aquellos hechos que pueden considerarse noticiables”. Pero, según reconoce el Tribunal Constitucional, "la expresión de pensamientos necesita a menudo apoyarse en la narración de hechos y, a la inversa, la comunicación de hechos o de noticias no se da nunca en un estado químicamente puro y comprende, casi siempre, algún elemento valorativo o, dicho de otro modo, una vocación a la formación de una opinión”. Y ello aconseja, “en los supuestos en que pueden aparecer entremezclados elementos de una y otra significación, atender, para calificar tales supuestos y encajarlos en cada uno de los apartados del artículo 20, al elemento que en ellos aparece como preponderante”. Si se aplica esto al ámbito de las relaciones laborales, el trabajador puede ejercitar cualquiera de ambos derechos, lo que dependerá en el supuesto concreto, tanto del medio de comunicación utilizado como de la naturaleza a otorgar a las manifestaciones realizadas por el trabajador, debiendo tenerse muy en cuenta que el hecho de que "algunas de las manifestaciones vertidas en torno a tales hechos entrañaran algún juicio de valor o alguna dosis de crítica no es suficiente para relativizar el carácter preponderante del elemento informativo".

— La segunda es la reelaboración, a la vista de la diferenciación entre libertad de expresión y libertad de información, en la relación existente entre la libertad de expresión y la buena fe contractual. Se parte de la premisa de que el trabajador se encuentra "sujeto, por razón de un contrato, a específicas obligaciones”, pero en esta resolución la combinación entre libertad de expresión y libertad de información permite un mayor campo de actuación a los derechos fundamentales en juego. Y es que, dice el Tribunal Constitucional, "ningún deber contractual de buena fe obliga al trabajador a callar o a no difundir unos hechos que son jurídicamente ilícitos y que pudieran constituir una inconstitucional discriminación”. El deber de buena fe del trabajador "no se puede interpretar en términos tales que vengan a resultar amparadas por esta exigencia de honestidad y de lealtad en el cumplimiento de las 
obligaciones, situaciones o circunstancias que, lejos de corresponderse con el ámbito normal y regular de prestación de trabajo, supondrían desviaciones de tal normalidad, merecedoras, acaso, de la reacción que a todos los ciudadanos cumple para hacer valer el imperio de las normas, cuando se aprecie una contravención del ordenamiento, o para hacer llegar a la opinión pública la existencia de eventuales anomalías que, aun no constitutivas, en sí, de ilicitud alguna, si pudieran llegar a poner en juego el principio de responsabilidad que pesa sobre todos los poderes públicos. Las anomalías que pudieran producirse en el funcionamiento de un organismo público requieren tanto su reparación o corrección como su conocimiento por la opinión pública, a cuyo servicio está la libertad consagrada en el artículo 20.1 d) de la CE”.

Hemos de añadir, en relación con esta STC 6/1998, de 21 de enero, un aspecto que, si bien aparece más destacadamente en la doctrina sentada por la STC 146/2019, de 26 de noviembre - y a ello nos vamos a referir en el Epígrafe III—, también surge en esta al hilo de los argumentos que acabamos de transcribir y en los cuales la doctrina laboralista vio una recepción de la figura del whistleblower, y de la protección que merece ${ }^{25}$. Doctrina constitucional que, como no podía ser de otra manera, es aplicada por los tribunales $\operatorname{ordinarios}^{26}$.

(3) Un tercer aspecto esencial de la jurisprudencia constitucional en la materia se deriva de la diferenciación entre libertad de expresión y libertad de información que conduce a una diferencia en los límites de una y otra, y esta diferencia de límites permite entender la trascendencia de las dificultades de precisar en la práctica si estamos ante el ejercicio de una u otra libertad. Un buen ejemplo de estas dificultades y de la trascendencia de la diferenciación lo encontramos en la STC 4/1996, de 16 enero. En ella, un trabajador del Metro de Madrid publicó una carta al director en dos periódicos de tirada nacional (El País y El Mundo) en las que criticaba la realización de horas extraordinarias en la empresa, que cifraba en 1.700.000 cuando es que solo se habían realizado, según la empresa, 132.855 horas, razón por la cual fue sancionado con suspensión de empleo y sueldo por una infracción muy grave. Aquí el Tribunal Constitucional nos advierte de nuevo en que el deslinde entre la libertad de expresión y la libertad de información "no es nítido, pues la expresión de la propia opinión necesita a menudo apoyarse en la narración de hechos y, a la inversa, la comunicación de hechos o noticias comprende casi siempre algún elemento valorativo, una vocación a la formación de una opinión. Por ello, en los supuestos en que se

${ }^{25}$ Cfr. BOZA PRO, G., El deber de sigilo de los representantes de los trabajadores, Valencia, 1997, págs. 435 a 446.

${ }^{26}$ De manera ejemplar, esta doctrina es aplicada en una sentencia del TSJ Andalucía (Sevilla) de 2 de octubre de 2007 (Rec. núm. 63/2007). Razona la sala sevillana que "el actor actuó como whistleblower, no ofendió al empresario, sino que se trata de empleado (al cabo despedido) que entrega fotos a un directivo de la empresa, sin que los hechos trasciendan mas allá del ámbito de ambas personas, por presunto fraude, es decir se lo comunica previa y únicamente a los interesados”, y añade que al actor "le animaba la defensa de la legalidad y no una intención de lucro o prevalimiento sobre una información comprometedora para la empresa, que expresamente se da por no probada”. Todo ello, añadido al reconocimiento expreso de la improcedencia del despido, conduce a la sala sevillana a concluir la existencia de vulneración de derecho fundamental. 
mezclan elementos de una y otra significación debe atenderse al que aparezca como preponderante o predominante para subsumirlos en el correspondiente apartado del artículo 20.1 CE”. Y si el trabajador “quiere situarse bajo la protección del artículo 20.1 d) CE, tiene un especial deber de comprobar la veracidad de los hechos que expone mediante las oportunas averiguaciones y empleando la diligencia exigible a un profesional. Puede que, pese a ello, la información resulte inexacta, lo que no puede excluirse totalmente, pero la información rectamente obtenida y difundida es digna de protección, aunque su total exactitud sea controvertible o se incurra en errores circunstanciales que no afecten a la esencia de lo informado". Ha de ponderarse, pues, "el alcance del errar en que se haya incurrido y tener presente además que el contraste de la noticia no es un término unívoco, sino que, más allá de su genérica formulación como deber, exige matizaciones casuísticas. Así, una de las circunstancias que modulan dicha obligación es la fuente que proporciona la noticia, porque si reviste características objetivas que la hacen fidedigna, seria o fiable puede no ser necesaria mayor comprobación que la exactitud o la identidad de la fuente”. Todas las anteriores consideraciones conducen, en este caso, a la estimación del recurso amparo constitucional porque "sin desdeñar la importancia del yerro numérico deslizado, este no afecta a la finalidad fundamental del mensaje transmitido, porque el elevado número de horas extraordinarias realmente realizadas permitía asimismo dar ocupación a personas desempleadas, si bien en una cifra sensiblemente inferior”; además estaba el hecho de que el trabajador no se había inventado la cifra de las horas extraordinarias realizadas, sino que la había tomado de las declaraciones de uno de los miembros del comité de empresa en el curso de una asamblea: "no resulta razonable dudar de la fiabilidad de lo transmitido a sus representantes por uno de los receptores directos de la información que legalmente suministra la propia empresa, ni exigir en consecuencia verificar su exactitud por otros cauces antes de reproducirlos, máxime teniendo encuentra la menor intensidad del deber de diligencia que, frente a los cánones de la profesionalidad informativa, es exigible al ciudadano”.

La STC 204/1997, de 25 de noviembre, nos vuelve a situar en la importancia de la distinción y en la trascendencia que la misma presenta, resultando que en esta sentencia se resuelve la cuestión atendiendo a los límites de la libertad de expresión que a los límites de la libertad de información. Se trataba aquí de un trabajador de TVE, S.A., que publicó en un periódico un escrito fuertemente crítico contra el ente público, imponiéndosele una sanción de suspensión de empleo y sueldo por este y otros hechos; más adelante, y a consecuencia de unas declaraciones a una cadena de radio, también de contenido muy crítico, fue despedido disciplinariamente. De nuevo, el máximo intérprete de nuestra Constitución diferencia "la amplitud de ejercicio de los derechos reconocidos en el artículo 20 CE según se trate de libertad de expresión (en el sentido de la emisión de juicio y opiniones) y libertad de información (en cuanto a la manifestación de hechos)”. Con relación a la primera, "al tratarse de la formulación de opiniones y creencias personales, sin pretensión de sentar hechos o afirmar datos objetivos, dispone de un campo de acción que viene delimitado por la ausencia de expresiones indudablemente injuriosas y que resulten innecesarias para la exposición de las mismas y que no contravengan otros valores 
constitucionales o derechos fundamentales, tales como la igualdad, dignidad o el derecho a la intimidad. En este sentido, los pensamientos, ideas, opiniones o juicios de valor, a diferencia de lo que ocurre con los hechos, no se prestan, por su naturaleza abstracta, a una demostración de su exactitud y ello hace que al que ejercita la libertad de expresión no le sea exigible la prueba de la verdad o diligencia en su averiguación, y, por tanto, respecto del ejercicio de la libertad de expresión no opera el límite interno de veracidad”. Pues bien, en el caso de esta sentencia el recurso de amparo resulta desestimado porque el ejercicio de la libertad de expresión se acompañó de expresiones insultantes (a los directivos les llamó “sanguijuelas” y “que se cagan en el personal”).

Vamos a detenernos, finalmente, en la STC 181/2006, de 19 de junio, porque en la STC 146/2019, de 26 de noviembre, se la cita como precedente destacado. El supuesto es el de una trabajadora sancionada por promover y firmar un escrito difundido dentro de la empresa criticando la gestión laboral de la empresa de atención a mayores en la que estaba empleada. Aquí se cuestiona el tema de la legitimidad del ejercicio de la libertad de expresión de la trabajadora, pues se considera que esta libertad es la predominante en el caso concreto, dado que "lo que los trabajadores hacen en su escrito es presentar una queja, manifestar su malestar, plantear, si se quiere, una reivindicación laboral, exponentes inequívocos, en cualquiera de los casos, de un acto de ejercicio del derecho a la libertad de expresión en el ámbito de las relaciones laborales: los firmantes no informan a la dirección de la empresa de unos hechos, pues tales hechos, fueran efectivamente conocidos o no por la concreta persona a la que se dirige la carta, se refieren a actuaciones de la propia empresa en cuanto tal, sino que ponen en su conocimiento la consideración que los mismos les merecen”. La premisa de partida es que "la libertad de expresión, que no es un derecho ilimitado y absoluto, como no lo es ninguno de los derechos fundamentales, debe conciliarse, cuando se ejerce en el marco de una relación de trabajo, con la lícita protección de los intereses empresariales, deducidos estos conforme a un juicio de ponderación, de manera que las restricciones que hayan de aplicarse habrán de ser adecuadas, imprescindibles y proporcionales a la protección de la libertad de empresa”. Partiendo de estas consideraciones en el caso enjuiciado en esta resolución se llega a la conclusión de que, en el caso enjuiciado, la conducta de la recurrente se desarrolló en todo momento dentro de los márgenes que delimitan el legítimo ejercicio de su derecho fundamental a la libertad de expresión reconocido en el art. 20.1 a) CE, tanto en lo que se refiere a sus límites genéricos, como a los específicos derivados del vínculo contractual. Y ello —que conduce a estimar el recurso de amparo - se concluye en base a tres consideraciones a tener en cuenta.

La primera de ellas resulta ser la ausencia de difusión pública del escrito: la demandante de amparo y los demás firmantes del escrito dirigen el mismo a su empresario, única y exclusivamente. Se trata, por tanto, de una mera comunicación interna en el seno de la empresa, sin que en ningún momento se haya ni siquiera alegado la existencia de cualquier tipo de difusión externa, ni respecto de la opinión pública en general, ni respecto 
de los usuarios del centro o sus familias, ni respecto de los responsables de la administración autonómica propietaria del centro y destinataria de la gestión.

En segundo término, el carácter estrictamente laboral del contenido del escrito considerado pues el mismo se refiere íntegramente a cuestiones tales como la formación profesional, los permisos, las bajas laborales, los comportamientos de la dirección en la gestión de los recursos humanos, las insuficiencias de personal, etc. En ningún momento el documento aborda cuestión alguna relacionada con otros ámbitos de la gestión empresarial, del mismo modo que se realiza imputación o crítica a la dirección del centro no relacionada directamente con su actuación en las relaciones laborales.

Y, en fin, la tercera de tales consideraciones es la ausencia de daño a los intereses empresariales. En la medida en que el escrito no hace otra cosa que manifestar el malestar de los trabajadores firmantes por la situación que denuncian, ningún daño efectivo a la empresa puede derivarse del mismo, pues habrá de ser en todo caso la citada situación de malestar la que pueda plantear dificultades en el funcionamiento del centro, no el poner su existencia en conocimiento de los responsables de la empresa y recabar la búsqueda de soluciones al respecto.

\section{LA SENTENCIA 146/2019, DE 26 DE NOVIEMBRE, DEL TRIBUNAL CONSTITUCIONAL: SU SUPUESTO DE HECHO Y LA SOLUCIÓN A QUE SE LLEGA EN SU FALLO}

El supuesto de hecho de la STC 146/2019, de 26 de noviembre, es el de un enfermero de centro de día que primero había sido sancionado por la empresa alegando que era "contrario a la buena fe contractual el hecho de que hubiese acudido al ayuntamiento de Baracaldo a trasladar una serie de cuestiones sobre su puesto de trabajo, sobre el centro en el que prestaba servicios y sobre esa empresa ... (porque) aunque fuese el ayuntamiento el titular del centro de día en el que trabajaba, no tenía con él vinculación laboral alguna, y que debió acudir a su empresa para efectuar tales quejas”, y que pocos días después fue despedido, alegando ahora falta muy grave de indisciplina o desobediencia en el trabajo, disminución continuada y voluntaria en el rendimiento de trabajo pactado y transgresión de la buena fe contractual ya que "se había comprobado que su rendimiento era un 70 por 100 inferior al de la media de sus compañeros, y que sus resultados y calidad del servicio eran muy poco satisfactorios para la empresa”; se precisaba, en tal sentido, que uno de los motivos de la adopción de esa decisión era su mala comunicación con el equipo y con sus superiores, en tanto que ni les trasladaba las incidencias de su puesto o de la marcha del centro, ni había hecho constar en las reuniones de equipo sus denuncias ante el titular del recurso en el que prestaba sus servicios, hechos que generaban gran desconfianza hacia su persona; y se le reprochaba también su actitud pasiva en las reuniones, y que no comunicara las conversaciones que tenía con los usuarios del centro o con sus familiares. 
Así las cosas, el Tribunal Constitucional dilucida con carácter previo cuál de los dos derechos implicados (libertad de expresión y libertad de información) se encontraba directamente concernido. En el presente caso, vistos los términos en los que se adoptó la decisión empresarial y el posterior debate procesal, el órgano judicial decidió centrar el debate en el concreto marco del derecho a la libertad de expresión, ya que "fueron las opiniones y juicios de valor del recurrente en amparo, y no el juicio sobre la veracidad y el carácter noticiable de los hechos en los que se pudieron apoyar, el fundamento de la decisión extintiva y el auténtico objeto de las resoluciones judiciales cuya revisión se solicita en este procedimiento constitucional”. De tal manera que "las quejas y reivindicaciones del recurrente en torno a la deficiente gestión de su centro de trabajo por su empleadora (adjudicataria del servicio municipal de atención de personas dependientes en el centro de día La Paz de Baracaldo) condujeron, en primer lugar, a su reprobación mediante una carta de advertencia de fecha 29 de abril de 2015, en la que se le exigía que tuviera el debido respeto a la empresa para la que trabajaba, que no realizara juicios de valor como los que había manifestado, y que no volviera a protagonizar incidentes como el relatado, o se tomarían medidas de mayor envergadura que la mera advertencia; en segundo lugar, y en conexión con esa amonestación que se consideró desatendida, se procedió después a su despido disciplinario el 25 de mayo siguiente, insistiendo aquella en la mala comunicación existente entre el trabajador y sus superiores, y en la desconfianza que les había generado sus denuncias ante el titular del servicio. Esto es, tanto la carta de advertencia como la posterior de despido vincularon la decisión extintiva a los juicios de valor y quejas formuladas por el trabajador en el ayuntamiento de Baracaldo, siendo, por consiguiente, el derecho a la libre expresión de los pensamientos, ideas y opiniones [el art. 20.1 a) de la Constitución Española] el que en este caso se ha visto afectado”.

Hecha esta identificación del derecho fundamental vulnerado, el Tribunal Constitucional entendió, en primer lugar, que no se transgredieron los límites del derecho a la libertad de expresión impuestos por el debido respeto a otros derechos fundamentales también dignos de protección, argumentando al efecto que "con sus manifestaciones, el trabajador se refirió estrictamente a cuestiones relativas al desarrollo de su relación laboral en el centro de trabajo, y, principalmente, a los problemas que tenía para el desempeño de sus funciones de enfermero derivados, principalmente, de la carencia de material sanitario y de otra índole. Y para expresar tales opiniones, no hay constancia ... de que utilizase expresiones ultrajantes u ofensivas que pudieran resultar impertinentes e innecesarias para el fin pretendido, o pudieran haber puesto en tela de juicio la probidad, ética, o prestigio profesional del empleador”.

En segundo término, al no haber excedido las manifestaciones del trabajador los límites genéricos que se imponen al ejercicio legítimo del derecho de libre expresión, el Tribunal Constitucional analizó su conducta teniendo en cuenta el límite adicional en el ejercicio del derecho constitucional impuesto por la relación laboral, que se deriva del principio de buena fe entre las partes en el contrato de trabajo y al que estas han de ajustar su comportamiento mutuo. Y para el alto tribunal la conducta empresarial supuso una 
“injustificada limitación del derecho a la libertad de expresión” del trabajador, en la medida en que:

(1) no se puede condicionar su ejercicio a que las críticas del trabajador respecto a su empresa tengan como único y posible receptor a esta última, por cuanto que "tal interpretación supone un claro vaciamiento del contenido del derecho fundamental”, que precisamente está caracterizado por otorgar a la persona el poder jurídico de expresar sus pensamientos, ideas y opiniones "libremente", siempre que se haga de forma respetuosa con los límites constitucionalmente impuestos al ejercicio del derecho; y

(2) la conducta sancionada no ha resultado contraria a la "buena fe contractual" o al "deber de lealtad" hacia la empresa, al haber formulado el trabajador sus quejas "en primer lugar y ante todo, frente a su propia empleadora, y que, solo una vez desatendidas sus reivindicaciones las formulase, en segundo lugar, ante el propio ayuntamiento, que como titular del centro de trabajo y contratante de los servicios de la empresa podía hacer que sus peticiones fueran atendidas; de este modo hay que concluir que la reclamación del trabajador había sido formulada ante quien debía dirigirse”.

En definitiva, el Tribunal Constitucional afirma que "no puede ser óbice para alcanzar tal conclusión sobre la legitimidad de la conducta del trabajador, el que las reivindicaciones laborales formuladas pudieran tener mayor o menor fundamento. Como ha quedado previamente apuntado, encontrándonos ante el ejercicio del derecho a la libertad de expresión, las opiniones o juicios de valor emitidos por el trabajador en torno a la gestión empresarial de su centro de trabajo no se prestaban — a diferencia de lo que ocurre con la libertad de información - a una demostración de su exactitud y prueba de veracidad”.

\section{LO QUE ES MÁS DESTACABLE: EL USO DE LA DENUNCIA INTERNA COMO ELEMENTO PARA VALORAR LA BUENA FE Y LA DIRECTIVA WHISTLEBLOWING}

Vista la fundamentación jurídica de la STC 146/2019, de 26 de noviembre, esta entronca a las claras con la previa jurisprudencia constitucional sobre la materia, aunque con un aspecto destacable que, si bien ya aparecía en la STC 6/1998, aquí resulta ser todavía más evidente: el demandante de amparo en la STC 146/2019, de 26 de noviembre, es, dicho en sus propios términos, un whistleblower, esto es un denunciante de irregularidades cometidas dentro del seno de una empresa. Además, mientras que la sentencia 6/1988, de 21 de enero, no hacía hincapié en la utilización de canales internos o externos de denuncia antes de la revelación pública - lo que podría llevar a la conclusión, como se verá errónea, de la irrelevancia de su uso-, la sentencia 146/2019, de 26 de noviembre, nos demuestra que ello no es dato en absoluto irrelevante, sino al contrario esencial a los efectos de valorar la buena fe de la denuncia, lo que conecta con la Directiva 
Whistleblowing y abre el camino a su debida aplicación en cuanto la misma se haya transpuesto correctamente.

Hagamos un somero acercamiento a la Directiva Whistleblowing para comprobar que, en efecto, el acudir a canales internos o externos de denuncia antes de acudir a la revelación pública, es algo trascendente a la hora de valorar la legitimidad del ejercicio de la libertad de expresión. Y es que la Directiva contempla tres maneras de canalizar las denuncias: (1) mediante denuncias internas; (2) mediante denuncias externas; y (3) mediante revelación pública. Se trataría, en suma, del sistema denominado tree-tiered aproach (tres escalones), que, a fuerza de ser sinceros, estaba más claramente definido en la Propuesta de Directiva y que, debido a ciertas críticas recibidas durante su tramitación, se ha diluido, pero no del todo.

(1) Denuncias internas. La Directiva —en su artículo 7, apartado 1- establece como "principio general" que la "información sobre infracciones podrá comunicarse a través de los canales y procedimientos de denuncia interna previstos en el presente capítulo”. Calificar a los canales de denuncia interna como principales y a los demás (denuncia externa y revelación pública) como residuales nos pone sobre la pista de que este tipo de denuncias internas son las que quiere potenciar la Directiva. Su Considerando 47 es claro al respecto: "Por principio, debe animarse a los denunciantes a utilizar en primer lugar los canales de denuncia interna e informar a su empleador, si dichos canales están a su disposición y puede esperarse razonablemente que funcionen”. Y es que los denunciantes se sienten más cómodos denunciando por canales internos, a menos que tengan motivos para denunciar por canales externos. Estudios empíricos “demuestran que la mayoría de los denunciantes tienden a denunciar por canales internos, dentro de la organización en la que trabajan”; además, "la denuncia interna es también el mejor modo de recabar información de las personas que pueden contribuir a resolver con prontitud y efectividad los riesgos para el interés público” — según se afirma en el Considerando 33-.

Conocida ya la preferencia de la norma por la denuncia interna, se comprende perfectamente que en la Directiva se exija a los Estados miembros promover "la comunicación a través de canales de denuncia interna antes que la comunicación a través de canales de denuncia externa, siempre que se pueda tratar la infracción internamente de manera efectiva y siempre que el denunciante considere que no hay riesgo de represalias" artículo 7, apartado 2-. Se trata de una imposición legal, sí, y dirigida a los Estados miembros, pero que presenta una doble condición: la empresa debe poder tratar la infracción denunciada de manera efectiva en su seno, y además el denunciante debe contar con que no será objeto de represalias. Es decir, que el empresario debe poner a disposición del trabajador un canal efectivo de denuncias que garantice la confidencialidad, de tal manera que el trabajador denunciante goce de una razonable expectativa de que la denuncia será tratada de una manera efectiva sin existir un riesgo de represalias ${ }^{27}$.

${ }^{27}$ Y es que "solamente si los empleados perciben un auténtico compromiso de la empresa se decidirán a revelar sus sospechas” (GARCÍA-MORENO GARCÍA DE LA GALANA, B., Los alertadores: una 
Mediante dicha exigencia legal, que obliga a los Estados miembros de la Unión Europea a promover sistemas internos de denuncias con esa doble condición, la Directiva, de manera refleja, está exigiendo a las empresas la implementación de procedimientos internos que sean adecuados para la recepción y el seguimiento de denuncias, que animen a los potenciales denunciantes a hacerlo sin temor a represalias, y que los convenza incluso de que sus denuncias contribuirán a la autocorrección y a la excelencia dentro de la empresa. Por eso mismo, la comunicación resulta aquí esencial ${ }^{28}$. La empresa debe facilitar a sus trabajadores la denuncia de irregularidades, y además debe procurar que el denunciante tenga la razonable expectativa de que su denuncia será tramitada y de que llegará a conocimiento del empresario, y que este hará lo adecuado para tratarla, sin que en ningún caso el trabajador pueda razonablemente temer represalias de ningún tipo.

También la Directiva —en su artículo 7, apartado 3- aborda el tema de la información para imponerle a los Estados miembros la obligación de proporcionar información apropiada relativa al uso de canales de denuncia interna en el contexto de la información proporcionada por las entidades jurídicas de los sectores privado y público, y por las autoridades competentes a todo aquel que haya acudido a la denuncia externa. De este modo, si quien pretende denunciar se decide por la denuncia externa, se le debe informar, por las entidades privadas y públicas y por las autoridades competentes, de que hay canales internos en principio preferentes para realizar la denuncia.

(2) Denuncia externa. No obstante, la preferencia de la denuncia interna, con las obligaciones accesorias de implementar sistemas internos de denuncias y de informar sobre los distintos canales de denuncia, la Directiva no obliga a acudir a ella antes de acudir a la denuncia externa para que la persona denunciante pudiera acceder a la protección frente a represalias. En la Propuesta de Directiva, sí había esa obligación salvo cuando el canal interno no funcionara o no se pudiera esperar razonablemente que funcionara. Tal postura más exigente se justificaba en garantizar que la información llegara a quienes podían contribuir a la pronta y efectiva resolución, y a la vez que se evitaran daños reputacionales injustificados.

Pero se realizaron críticas desde diversas instancias. El Comité Económico y Social Europeo recomendaba sustituir el sistema de tres etapas por uno de dos etapas, de forma que el alertador pudiera elegir a su preferencia entre el canal interno y el externo como primera etapa, y posteriormente, si fuera necesario, acudiera a la sociedad civil y los

propuesta de regulación, tesis doctoral, Ciudad Real, 2018, pág. 291, accesible en https:// ruidera.uclm.es, consulta: 15/05/2020). De esta misma autora también ver GARCÍA-MORENO GARCÍA DE LA GALANA, B., Del whistleblower al alertador. La regulación europea de los canales de denuncia, Valencia, 2020.

${ }^{28}$ La doctrina ha indicado que "el canal de denuncias debe ser divulgado previa y efectivamente entre sus destinatarios” (ESPÍN MARTÍ, R., El canal de denuncias internas en la actividad empresarial como instrumento del compliance, tesis doctoral, Barcelona, 2017, pág. 435, accesible en https://ddd.uab.cat, consulta: 11/05/2020). 
medios de comunicación ${ }^{29}$. El Tribunal de Cuentas no criticó el sistema de tres etapas obligatorias denuncia interna / denuncia externa / revelación pública, pero sí la vaguedad con la cual se escalonaban el sistema interno y el externo ${ }^{30}$. Esas críticas han condicionado el resultado final, en la medida en que, no obstante, las afirmaciones reflejadas en el preámbulo de la norma comunitaria demostrativas de la preferencia al canal interno, en su parte dispositiva la relación con el canal externo se declina en clave de alternatividad a elección del denunciante. Y es que según el artículo 10 de la Directiva Whistleblowing, los denunciantes, sin perjuicio de la posibilidad de acudir a la revelación pública (en los términos que veremos más adelante), comunicarán información sobre infracciones por los canales de denuncia externa "tras haberla comunicado en primer lugar a través de los canales de denuncia interna, o bien comunicándola directamente a través de los canales de denuncia externa”. La literalidad de la norma coloca así al canal externo en relación de alternancia con el interno: el potencial denunciante puede acudir, a su voluntad, tanto al canal interno como al externo, sin que decidirse por uno u otro, o a ambos, haga merma en las garantías frente a represalias ${ }^{31}$.

Ahora bien, la Directiva, en su Preámbulo — en especial en los Considerandos 60 a 63-, no oculta de nuevo su preferencia por el canal interno en la medida en que acudir al canal externo se justifica en determinadas circunstancias: (1) en que no existan canales internos por no ser legalmente exigibles; (2) en que el denunciante no tenga la razonable convicción de que los canales internos vayan a funcionar adecuadamente, por ejemplo, cuando el responsable último de la empresa se encuentre implicado en la infracción, o cuando exista el riesgo de que se oculte la infracción, o cuando se sepa o se sospeche que se destruyen pruebas, o incluso cuando la infracción requiera medidas urgentes para proteger la vida, la salud y la seguridad de las personas; o (3) en que se hayan utilizado los canales internos, aparentemente eficaces, pero en el caso concreto no hayan funcionado correctamente, por ejemplo, cuando la denuncia no se haya seguido con diligencia o en un plazo razonable, o no se haya tomado ninguna medida adecuada para tratar la infracción a pesar del resultado de la correspondiente investigación confirmando la infracción denunciada.

(3) Revelación pública. Finalmente, la Directiva regula —en su artículo 15- la revelación pública de infracciones, permitiendo a quien la haga acogerse al sistema de

29 Dictamen del Comité Económico y Social Europeo sobre la Comunicación de la Comisión al Parlamento Europeo, al Consejo y al Comité Económico y Social Europeo - Reforzar la protección de los denunciantes en la UE y sobre la propuesta de Directiva del Parlamento Europeo y del Consejo relativa a la protección de las personas que informen sobre infracciones del Derecho de la Unión.

30 Dictamen del Tribunal de Cuentas núm. 4/2018, sobre la Propuesta de Directiva del Parlamento Europeo y del Consejo relativa a la protección de las personas que informen sobre infracciones del Derecho de la Unión (2018/C 405/01) (DOUE C405/1, 9 de noviembre de 2018).

${ }^{31}$ En palabras de la doctrina, "los procedimientos de denuncia externos no quedan supeditados a haber acudido previamente a los canales internos, por lo que el denunciante podrá optar por utilizar los cauces internos o formular la denuncia directamente frente a un órgano externo” (BACHMAIER WINTER, L., "Whistleblowing europeo y compliance: La Directiva EU de 2019 relativa a la protección de personas que reporten infracciones del Derecho de la Unión”, Diario La Ley, núm. 9539, 2019, pág. 5). 
protección frente a represalias en los dos siguientes supuestos: (1) la persona había denunciado por canales internos y externos (la revelación pública sería el tercer escalón), o directamente por canales externos (la revelación pública sería el segundo escalón), sin que se hubieran tomado medidas apropiadas al respecto dentro de un plazo de tres meses, o de seis meses en casos debidamente justificados si la denuncia ha sido externa; (2) de igual manera, y con independencia de la denuncia externa o interna, la protección debe garantizarse cuando la persona tenga motivos razonables para pensar que la infracción puede constituir un peligro inminente o manifiesto para el interés público, o en caso de denuncia externa, si existe un riesgo de represalias o hay pocas probabilidades de que se dé un tratamiento efectivo a la infracción debido a las circunstancias del caso.

Haber seguido en la denuncia el sistema de tres escalones (denuncia interna / denuncia externa / revelación pública) o de dos escalones (si voluntariamente se utiliza la denuncia externa en vez de utilizar la interna) marcado en la Directiva es lo que habilita para la protección que la misma regula en su capítulo VI y que comprende una prohibición de represalias —artículo 19- y disposiciones dirigidas a su efectividad en torno a los siguientes tópicos: medidas de apoyo —artículo 20-; medidas de protección frente a represalias —artículo 21—; medidas para la protección de las personas afectadas —artículo 22-; sanciones —artículo 23-; y prohibición de renuncia a los derechos y vías de recurso —artículo 24-.

Analizar los mecanismos de protección frente a represalias contemplados en la Directiva Whistleblowing excede ya del ámbito de este estudio, aunque no está de más apuntar que se sitúan en la misma línea de la prohibición de las represalias por vulneración del derecho a la libertad de expresión en que se sitúa la jurisprudencia constitucional en la materia. Lo que aquí queríamos destacar es que seguir el íter marcado por la Directiva, o salirse de él, es lo decisivo para garantizar la protección del denunciante frente a represalias por la denuncia de irregularidades. Y que esto casa a la perfección con los razonamientos utilizados en la sentencia 146/2019, de 26 de noviembre, que incluso va más allá cuando vincula la valoración de la buena fe de la persona denunciante de la irregularidad a la circunstancia de haber acudido en primer lugar a la denuncia interna, incluso antes de acudir a la denuncia externa (lo que nos sitúa en el original sistema de tres escalones). Sea como fuere, el espíritu de la sentencia 146/2019, de 26 de noviembre, conecta con el espíritu de la Directiva Whistleblowing y abre el camino a su debida aplicación en cuanto la misma se haya transpuesto correctamente. Algo que esperemos no tarde demasiado.

\section{BIBLIOGRAFÍA}

- BACHMAIER WINTER, L., "Whistleblowing europeo y compliance: La Directiva EU de 2019 relativa a la protección de personas que reporten infracciones del Derecho de la Unión”, Diario La Ley, núm. 9539, 2019. 
- BOZA PRO, G., El deber de sigilo de los representantes de los trabajadores, Valencia, 1997.

- CLIMENT GALLART, J.A., La jurisprudencia del Tribunal Europeo de Derechos Humanos sobre la libertad de expresión y el derecho al honor, Tesis Doctoral, Valencia, 2015 (http://roderic.uv.es).

- DEL REY GUANTER, S., Libertad de expresión e información y contrato de trabajo: Un análisis jurisprudencial, Madrid, 1994.

- DEL REY GUANTER, S., “La reciente doctrina del Tribunal Constitucional sobre la libertad de expresión e información en la relación laboral: extensión y límites”, en AA.VV. (LOUSADA AROCHENA, J.F. [coord.], y MOVILLA GARCÍA, M., [coord..]), Derechos fundamentales y contrato de trabajo, Granada, 1998.

- ESPÍN MARTÍ, R., El canal de denuncias internas en la actividad empresarial como instrumento del compliance, tesis doctoral, Barcelona, 2017 (https://ddd.uab.cat).

- GARCÍA-MORENO GARCÍA DE LA GALANA, B., Los alertadores: una propuesta de regulación, tesis doctoral, Ciudad Real, 2018 (https:// ruidera.uclm.es).

- GARCÍA-MORENO GARCÍA DE LA GALANA, B., Del whistleblower al alertador. La regulación europea de los canales de denuncia, Valencia, 2020.

- GORELLI HERNÁNDEZ, J. e IGARTUA MIRÓ, M.T., “Libertad de información y contrato de trabajo. El problema de sus límites. A propósito de la STC 57/1999, de 12 abril”, Aranzadi Social, vol. V, 1999.

- LOUSADA AROCHENA, J. F., y RON LATAS, R. P., La protección laboral frente a las represalias por la denuncia de irregularidades en la empresa (Whistleblowing), Albacete, 2020.

- PAZOS PÉREZ, A., El derecho a la libertad de expresión y el derecho a la libertad de información en el ámbito laboral, Valencia, 2014.

- RODRÍGUEZ-IZQUIERDO SERRANO, M. “La libertad de expresión y la jurisprudencia del Tribunal de Justicia de la Unión Europea”, Estudios de Deusto, Vol. 62/2, 2014. 